\title{
Rubeosis of the iris and haemorrhagic glaucoma in patients with proliferative diabetic retinopathy
}

\section{P. H. MADSEN}

From the Department of Ophthalmology and Internal Medicine, the University Hospital, Aarhus, $\vec{\circ}$ Denmark

Although abnormal iris vessels and secondary glaucoma in a patient with proliferative diabetic retinopathy was described over 80 years ago by Nettleship (1888), Salus (1928) was the first to call attention to rubeosis of the iris as a specific manifestation of long-term diabetes and to point out that the neovascularization of the iris resulted in haemorrhagic glaucoma.

Neovascularization of the iris and the chamber angle is far less frequent than retinal changes in diabetics. In nonselected groups of diabetics, rubeosis of the iris occurs in only a small percentage (Ohrt, I958; Armaly and Baloglou, I967). Most frequently, the iridic neovascularization appears in eyes with proliferative retinopathy (Janert, Mohnike, and Georgi, r957; Krüger, r96r ; Ohrt, r967; Madsen, r97 ra).

The purpose of this paper is to describe the occurrence of rubeosis of the iris and the development of this affection in diabetics with proliferative retinopathy.

\section{Material}

The series consists of 68 diabetics suffering from proliferative retinopathy. These patients were examined repeatedly during the years $1963^{-1} 1968$ in the Departments of Ophthalmology and Internal Medicine, the University Hospital, Aarhus. The examination was carried out by means of a slit lamp, often with great magnification, and red-free light. The site of the neovascularization was described in detail, in many cases accompanied by drawings for subsequent comparison.

Proliferative retinopathy had been present for years in most of the patients before the appearance of the rubeosis.

Hypophysectomy had been carried out in $3 \mathrm{I}$ of the patients. Further information on the 68 patients is given in the following paper (Madsen, $197 \mathrm{Ib}$ ).

\section{Results}

Rubeosis of the iris was seen in 58 eyes during the observation period. One of the eyes was removed on account of haemorrhagic glaucoma. At the last examination, rubeosis of the iris was observed in 42 eyes, but had disappeared in fifteen eyes (Table I, opposite).

In many patients, rubeosis of the iris may be unchanged for several years, or there may be fluctuation in the severity of the neovascularization. In nineteen patients, rubeosis of the iris had repeatedly been observed in 24 eyes without being followed by haemorrhagic glaucoma during the observation period. As shown in Table II, the observation time was up to 5 years. 
Table I Occurrence of rubeosis of the iris and haemorrhagic glaucoma in 135 eyes (last examination)

Rubeosis of the iris

$(+)$

$+$

$++$

Rubeosis previously observed

Haemorrhagic glaucoma

\begin{tabular}{|c|c|c|}
\hline \multicolumn{2}{|c|}{ Hypophysectomy } & \multirow{2}{*}{ Total } \\
\hline Performed & Not performed & \\
\hline $\begin{array}{r}44 \\
5\end{array}$ & $\begin{array}{r}49 \\
2\end{array}$ & $\begin{array}{r}93 \\
7\end{array}$ \\
\hline 8 & 12 & 20 \\
\hline 5 & 10 & 15 \\
\hline 4 & I I & I5 \\
\hline 5 & 8 & I3 \\
\hline
\end{tabular}

Stages: o No rubeosis

(+) Small vascular coils at pupillary border

$+\quad$ Greater vascular networks in annulus minor

++ Severe rubeosis with vessels on entire iris surface

Table II Rubeosis of the iris in 28 eyes without haemorrhagic glaucoma

\begin{tabular}{|c|c|c|c|c|c|c|}
\hline $\begin{array}{l}\text { Age } \\
(y r s)\end{array}$ & $\operatorname{Sex}$ & Eye & $\begin{array}{l}\text { Time of } \\
\text { observation } \\
\text { (mths) }\end{array}$ & Rubeosis of the iris & $\begin{array}{l}\text { Chamber } \\
\text { angle }\end{array}$ & Hypophysectomy \\
\hline \multirow[t]{2}{*}{45} & $\mathbf{F}$ & $\mathbf{R}$ & 39 & $(+)$ & - & + \\
\hline & & $\mathbf{L}$ & 39 & $(+)$ & - & + \\
\hline 30 & F & $\mathbf{R}$ & II & $(+) \rightarrow+$ & $?$ & + \\
\hline 30 & $\mathbf{M}$ & $\mathbf{R}$ & 7 & $(+) \rightarrow+$ & - & + \\
\hline 64 & $\mathbf{M}$ & $\mathbf{R}$ & 64 & + & - & + \\
\hline $5^{6}$ & $\mathbf{M}$ & $\mathbf{R}$ & 44 & + & $-\rightarrow$ o.v. & + \\
\hline 44 & $\mathbf{F}$ & $\mathbf{R}$ & $5^{\circ}$ & $(+)$ & - & + \\
\hline 32 & $\mathbf{M}$ & L & 35 & $+\rightarrow(+)$ & - & + \\
\hline 37 & $\mathbf{F}$ & $\mathbf{R}$ & 60 & $(+) \rightarrow+$ & - & \\
\hline $3^{8}$ & $\mathbf{M}$ & L & 48 & + & - & \\
\hline 37 & $\mathbf{F}$ & $\mathbf{L}$ & 7 & + & - & \\
\hline 40 & $\mathbf{F}$ & $\begin{array}{l}\mathbf{R} \\
\mathbf{L}\end{array}$ & $\begin{array}{l}37 \\
37\end{array}$ & $\begin{array}{l}+\rightarrow++\rightarrow+ \\
+\rightarrow++\rightarrow+\end{array}$ & - & \\
\hline 34 & $\mathbf{M}$ & $\mathbf{R}$ & 4 & $(+)$ & - & \\
\hline 23 & $\mathbf{F}$ & $\begin{array}{l}\mathbf{R} \\
\mathbf{L}\end{array}$ & $\begin{array}{l}23 \\
11\end{array}$ & $\stackrel{+}{-}+++\rightarrow+$ & $\begin{array}{l}-\overrightarrow{0 . v} \text {. } \\
\text { o.v. }\end{array}$ & \\
\hline 49 & $\mathbf{M}$ & L & 25 & $(+) \rightarrow+$ & - & \\
\hline 59 & $\mathbf{F}$ & $\mathbf{R}$ & 38 & + & - & \\
\hline 44 & $\mathbf{M}$ & $\mathbf{R}$ & 17 & $+\rightarrow(+)$ & - & \\
\hline 60 & $\mathbf{M}$ & $\mathbf{R}$ & $3^{1}$ & $+\rightarrow++$ & o.v. & \\
\hline 65 & $\mathbf{M}$ & $\begin{array}{l}\mathbf{R} \\
\mathbf{L}\end{array}$ & $\begin{array}{l}9 \\
9\end{array}$ & $\begin{array}{l}+ \\
+\end{array}$ & $\begin{array}{l}\text { o.v. } \\
\text { o.v. }\end{array}$ & \\
\hline 36 & $\mathbf{M}$ & $\mathbf{L}$ & $3^{8}$ & $++\rightarrow+$ & o.v. & \\
\hline
\end{tabular}

Key to abbreviations: $0 .=$ open angle $\quad$ v. = new-formed vessels in angle

Rubeosis of the iris occurred with almost the same frequency in hypophysectomized and nonhypophysectomized patients, as did the other signs of diabetic iridopathy, viz. porosity and atrophy of the pupillary border, atrophy of the iris, and deposits of pigment granules on the surface of the iris.

Haemorrhagic glaucoma occurred in fourteen eyes during the observation period. In our eyes, glaucoma was already present at the first examination; in ten eyes rubeosis of 
the iris was observed before the onset of haemorrhagic glaucoma. Table III shows the time interval between the appearance of rubeosis of the iris and the onset of the haemorrhagic glaucoma. This interval varied from $\mathrm{I}$ to 38 months.

Table III Time interval between detection of rubeosis iridis and occurrence of haemorrhagic glaucoma

\begin{tabular}{|c|c|c|c|c|c|c|}
\hline $\begin{array}{l}\text { Age } \\
(y r s)\end{array}$ & Sex & Eye & $\begin{array}{l}\text { Interval } \\
\text { (mths) }\end{array}$ & $\begin{array}{l}\text { Development } \\
\text { of rubeosis of } \\
\text { the iris }\end{array}$ & Chamber angle & Hypophysectomy \\
\hline 29 & $\mathbf{F}$ & L & I & $+\rightarrow+t$ & o.v. $\rightarrow$ cl. & + \\
\hline 32 & $\mathbf{M}$ & $\mathbf{R}$ & 12 & $+\rightarrow++$ & $-\rightarrow \mathrm{cl}$ & + \\
\hline 37 & $\mathbf{F}$ & $\mathbf{L}$ & 36 & $+\rightarrow++$ & $-\rightarrow$ o.v. & + \\
\hline \multirow[t]{2}{*}{32} & $\mathbf{M}$ & $\mathbf{R}$ & 27 & $+\rightarrow++$ & o.v. $\rightarrow$ cl.v. & \\
\hline & & $\mathbf{L}$ & 32 & $+\rightarrow++$ & $-\rightarrow$ cl.v. & \\
\hline 27 & $\mathbf{F}$ & $\mathbf{R}$ & 6 & $+\rightarrow++$ & - $\rightarrow$ cl.v. & \\
\hline 30 & $\mathbf{M}$ & $\mathbf{R}$ & I & $+\rightarrow++$ & $-\rightarrow$ o.v. & \\
\hline 49 & $\mathbf{M}$ & $\mathbf{R}$ & 13 & $+\rightarrow++$ & o.v. $\rightarrow$ o.v.syn. & \\
\hline 59 & $\mathbf{F}$ & L & 38 & $+\rightarrow++$ & $? \rightarrow$ cl. & \\
\hline 44 & $\mathbf{M}$ & L & 17 & ++ & $? \rightarrow \mathrm{cl}$ & \\
\hline
\end{tabular}

Key to abbreviations:

$$
\begin{array}{lc}
\text { o. = open angle } & \mathrm{cl} .=\text { closed angle } \\
\text { v. = new-formed vessels in angle } & \text { syn. }=\text { synechiae }
\end{array}
$$

Simple glaucoma was seen in only one patient (hypophysectomized). Otherwise, the $\stackrel{6}{\rightarrow}$ intraocular pressure was low in the great majority of the patients in this series. At the last examination, the average intraocular pressure in 54 nonglaucomatous eyes in the hypophysectomized patients was $12.5 \mathrm{~mm}$. $\mathrm{Hg}$, and in 61 eyes in the nonoperated patients the average was $13.3 \mathrm{~mm}$. $\mathrm{Hg}$.

Very low intraocular pressures were found in eyes in which haemorrhagic glaucoma later developed. In eight of the ten eyes in Table III, intraocular pressures of $10 \mathrm{~mm} . \mathrm{Hg}$ or less (applanation) were found in the period before the occurrence of the glaucoma. In this hypotonic phase, rubeosis of the iris developed, followed by a rise in the intraocular pressure, of sudden or more gradual onset. Such a case with hypotonia and subsequent development of haemorrhagic glaucoma is shown in the figure.

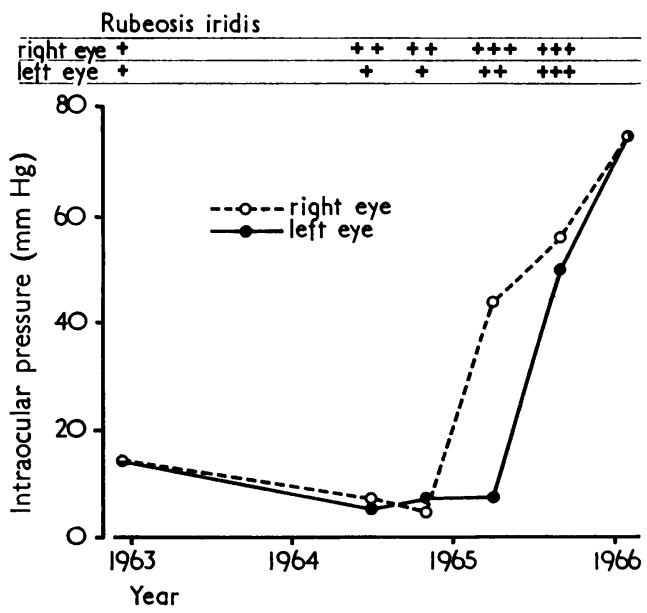

F I G U E Intraocular pressure and development of rubeosis iridis in a young man with proliferative diabetic retinopathy in both eyes 


\section{Discussion}

Rubeosis of the iris is relatively frequent in eyes with proliferative diabetic retinopathy, and occurred in 43 per cent. in the present series. It is a serious complication on account of the frequent concomitant occurrence of haemorrhagic glaucoma. This form of glaucoma supervened in fourteen of the $5^{8}$ eyes with iridic neovascularization during the observation period.

It is shown that, in some eyes, rubeosis of the iris may run a very slow course. There may be periods of exacerbation or regression, or the new-formed iridic vessels may eventually disappear, as has also been demonstrated in other series (Ohrt, 1967). In all cases under observation, haemorrhagic glaucoma occurred after the development of neovascularization in the iris and chamber angle. No case of secondary rubeosis was seen.

Hypotonia seems to be an important factor in the development of rubeosis of the iris and the subsequent haemorrhagic glaucoma.

\section{Summary}

In a series of 68 patients with proliferative diabetic retinopathy, rubeosis of the iris was observed in $5^{8}$ eyes, including 22 in patients who had been subjected to hypophysectomy during an observation period of up to 5 years. Haemorrhagic glaucoma occurred in fourteen eyes.

\section{References}

ARmaly, M. F., and baloglou, P. J. (1967) Arch. Ophthal. (Chicago), 77, 485

JANERT, H., MOHNIKE, G., and GEORGI, P. (1957) Klin. Wschr., 35, I IO

KRÜGER, K. E. (I96I) Ophthalmologica (Basel), 142, Suppl., "I Congr. Soc. europ. Ophtal., Athènes 1960 : Le glaucome secondaire", ed. J. François, p. 604

MADSEN, P. H. (1971 Ia) Brit. F. Ophthal., 55, 444

(197 I b) Brit. 7. Ophthal., 55, 372

NETTLESHIP, E. (1888) Trans. ophthal. Soc. U.K., 8, I59

OHRT, v. (1958) Acta ophthal. (Kbh.), 36, 556

(1967) “Diabetic Iridopathy", p. 91. Universitetsforlaget, Aarhus, Denmark.

salus, R. (1928) Med. Klin., 24,256 